\title{
Effect of texturing on the magnetically activated properties of polycrystalline NiMnGa alloys
}

\author{
M. Pasquale, C.P. Sasso, S. Besseghini ${ }^{1}$, F. Passaretti ${ }^{1}$, E. Villa ${ }^{1}$ \\ and V.A. Chernenko ${ }^{2}$ \\ IEN Galileo Ferraris Torino, 10125 Torino, Italy \\ ${ }^{1}$ Cnr-TeMPE Sezzione di Lecco, 23900 Lecco, Italy \\ ${ }^{2}$ Institute of Magnetism, 03142 Kiev, Ukraine
}

\begin{abstract}
We present structural and magnetostrain data obtained on as cast and annealed bulk polycrystalline $\mathrm{Ni}_{2} \mathrm{MnGa}$ samples with a defined grain orientation. A peak cyclic strain of the order of $10^{-4}$ is found, due to the readjustment of martensite structures under applied field. Annealing may produce positive effects on the austenite to martensite transition and on strain. These experimental results are discussed with reference to previously published data on single crystals and randomly oriented polycrystalline samples.
\end{abstract}

\section{INTRODUCTION}

Ferromagnetic shape memory alloys, have been shown to produce giant strains up to $6 \%$ in single crystal form due to the motion of martensite twin boundaries caused by an external magnetic field. Such strain is at least one order in magnitude larger than strain achievable with rare earth magnetostrictive materials, and the possibility of application in devices is widely studied. Many interesting results have been reported in the literature on single crystals and thin films [1-5] while the available information concerning polycrystalline systems is still quite limited. In the present work we present the results of magnetically induced strain behavior of polycrystalline samples with a defined texturing, induced by casting the melt in a copper mold. Texture and chemical composition are chosen for simplicity of processing and possible use as actuators not far from room temperature. The samples are fully characterized in the as-prepared state and after the annealing treatments. It is shown that the characteristics of the austenite-martensite transition and also the maximum cyclic strain obtained under a magnetic field are deeply influenced by the annealing treatments in a non trivial way. The peak strain obtained is rather small $\varepsilon \approx 10^{-4}$, a result similar to other non-oriented polycrystalline samples.

\section{SAMPLE PREPARATION AND STRUCTURAL ANALYSIS}

Nearly stoichiometric $\mathrm{Ni}_{2} \mathrm{MnGa}$ Master alloy samples are prepared by induction melting of high purity elements. Several compositions are obtained and thoroughly characterized by scanning electron microprobe (Energy Dispersive Spectroscopy, EDS), differential scanning calorimetry (DSC) and optical microscopy. The master alloy $\mathrm{Ni}_{54} \mathrm{Mn}_{21} \mathrm{Ga}_{25}$ is chosen for further characterization, and shows a martensitic transition temperature $\mathrm{M}_{\mathrm{f}}$ of $-3{ }^{\circ} \mathrm{C}$ and a Curie point around $70^{\circ} \mathrm{C}$, allowing for rather simple characterization. A cylindrical sample of $10 \mathrm{~mm}$ diameter and several $\mathrm{cm}$ long is obtained with a radial crystalline structure, produced by casting the alloy in a copper mold. The cylinder is spark cut in round slices of $1 \mathrm{~mm}$ thickness for further characterization and thermal treatments. Two treatments at $800{ }^{\circ} \mathrm{C}$ of $5 \mathrm{~h}$ and $72 \mathrm{~h}$ are applied, in order to homogenize the samples and allow for grain growth. A composition check with EDS is performed after the treatment. Optical microscopy (OM) shows a radial columnar structure with a $60 \mu \mathrm{m}$ grain size, produced during the primary cooling of the melt. After annealing for 5 $\mathrm{h}$ and $72 \mathrm{~h}$ at $800^{\circ} \mathrm{C}$ the grain size respectively increases to $100 \mu \mathrm{m}$ and $150 \mu \mathrm{m}$ see figure 1. 

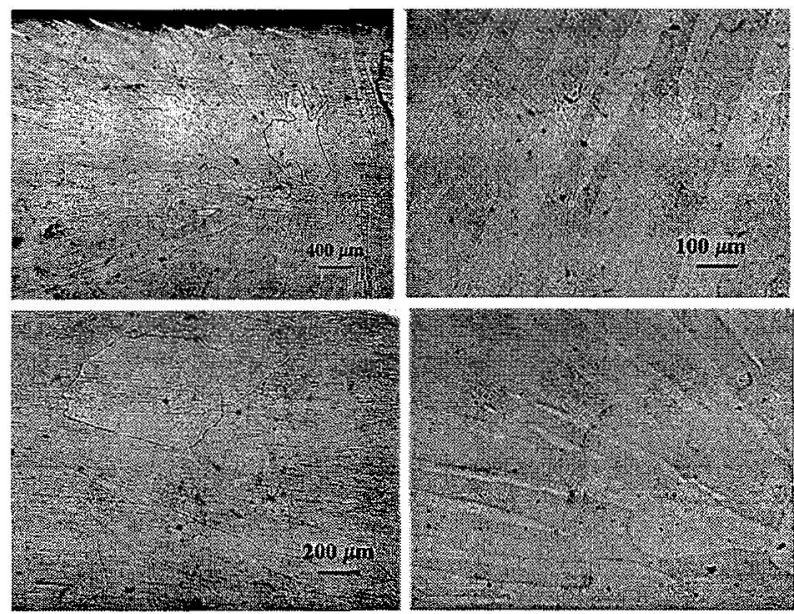

Fig. 1 Room temperature micrographs obtained on grain oriented $\mathrm{Ni}_{\$ 4} \mathrm{Mn}_{21} \mathrm{Ga}_{25}$ in austenite phase, before and after the annealing treatments. Top left: (magnification $25 \mathrm{X}$ ) overview of the sample surface after $5 \mathrm{~h}$ annealing, with a radial structure departing from the sample center (on the right hand side). Top right: as prepared sample $(100 \mathrm{X})$, average grain size $60 \mu \mathrm{m}$. Bottom left: $800^{\circ} \mathrm{C}, 5 \mathrm{~h}$ annealing in $\operatorname{Ar}(50 \mathrm{X})$ Average grain size $100 \mu \mathrm{m}$. Bottom right: $(25 \mathrm{X}) 72 \mathrm{~h}$ annealing in $\mathrm{Ar} 800^{\circ} \mathrm{C}$, average grain size $150 \mu \mathrm{m}$.

Typical martensite twin structures are achieved after cooling under the final martensite transition temperature $\mathrm{M}_{\mathrm{f}}=-3^{\circ} \mathrm{C}$. DSC measurements performed before and after annealing demonstrate the effect of thermal treatments on the properties of the martensitic transformation. An improvement in the phase transformation properties is obtained through an increasing annealing time, as depicted by DSC peak sharpening and a small temperature shift of the martensite peaks (figure 2). Data shown in figure 2 is summarized in table 1 . For the sake of comparison a single crystal of $\mathrm{Ni} 2 \mathrm{MnGa}\left(\mathrm{Ms}=-98^{\circ} \mathrm{C}\right)$ used in [6] was also measured.

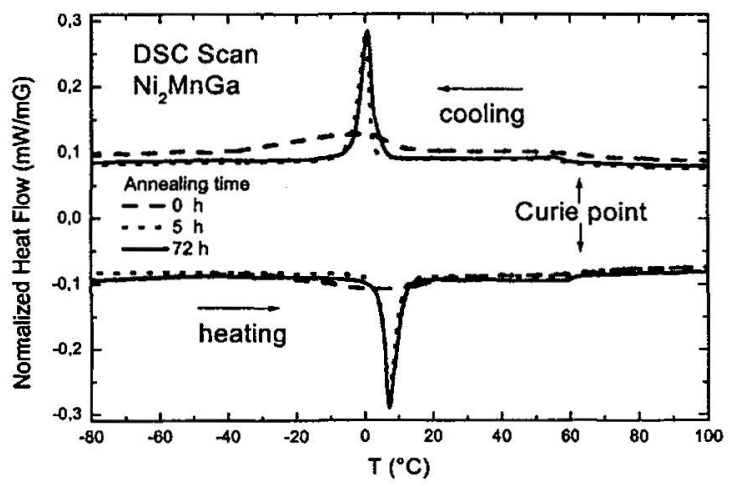

Fig. 2 Differential scanning calorimetry (heating and cooling) runs on the three samples of $\mathrm{Ni}_{54} \mathrm{Mn}_{21} \mathrm{Ga}_{25}$, as prepared and heat treated at $800^{\circ} \mathrm{C}$ for 5 and 72 hours. Annealing produces a peak sharpening. The $72 \mathrm{~h}$ cooling run shows a peak spread, possibly connected with some structural rearrangement and higher content of elastic energy. 
Table 1: Characteristics of NiMnGa textured polycrystalline samples. $\mathrm{t}(\mathrm{h})$ annealing time at $800^{\circ} \mathrm{C}$ in $\mathrm{Ar},<\mathrm{s}>(\mu \mathrm{m})$ average grain size, $\varepsilon\left(10^{-6}\right)$ max strain obtained in a cycle, martensite transition temperatures during cooling $\mathrm{M}_{\mathrm{s}}, \mathrm{M}_{\text {peak }}\left({ }^{\circ} \mathrm{C}\right), \mathrm{M}_{\mathrm{f}}\left({ }^{\circ} \mathrm{C}\right)$, and heating $\mathrm{A}_{\mathrm{s}}\left({ }^{\circ} \mathrm{C}\right), \mathrm{A}_{\text {peak }}\left({ }^{\circ} \mathrm{C}\right) \mathrm{A}_{f},\left({ }^{\circ} \mathrm{C}\right), \mathrm{T}_{\mathrm{C}}\left({ }^{\circ} \mathrm{C}\right)$ Curie temperature (through DSC).

\begin{tabular}{|c|c|c|c|c|c|c|c|c|c|}
\hline $\mathrm{t}(\mathrm{h})$ & $<\mathrm{s}>$ & $\varepsilon$ & $\mathrm{M}_{\mathrm{s}}$ & $\mathrm{M}_{\text {peak }}$ & $\mathrm{M}_{\mathrm{f}}$ & $\mathrm{A}_{\mathrm{s}}$ & $\mathrm{A}_{\text {peak }}$ & $\mathrm{A}_{\mathrm{f}}$ & $\mathrm{T}_{\mathrm{C}}$ \\
\hline- & 60 & -50 & 11.8 & -1.2 & -35.7 & -26 & 8.1 & 24.6 & 74.7 \\
\hline 5 & 100 & -90 & 2.2 & 0.2 & -3.8 & 4.3 & 7.3 & 10.6 & 63.9 \\
\hline 72 & 150 & -40 & 3.3 & 0.8 & -3 & 3.9 & 7.5 & 11.4 & 62.5 \\
\hline
\end{tabular}

\section{MAGNETO-STRAIN PROPERTIES}

First of all we would like to point out that the data presented in the following may serve in the comparison with other magnetostrictive materials and may not be directly compatible or even comparable with typical $\mathrm{Ni}_{2} \mathrm{MnGa}$ results presented in the literature. To our knowledge, magnetic field can produce a repeatable strain above $1 \%$ in $\mathrm{NiMnGa}$ single crystals only if the field is ramped up along one direction and then along another one at a $90^{\circ}$ angle. Other configurations which have been shown to produce large cyclic strain may need a cyclic application of stress to achieve reorientation of the martensite twins.

In our case several rectangular samples $10 \mathrm{~mm} \times 3 \mathrm{~mm} \times 1 \mathrm{~mm}$ are spark cut from round slices of the original cylinder. One resistive strain gauge is longitudinally bonded on the edge of each sample, where the texture is better defined. Given the nominal composition $\mathrm{Ni}_{54} \mathrm{Mn}_{21} \mathrm{Ga}_{25}$ with an $\mathrm{M}_{\mathrm{f}} \sim-3{ }^{\circ} \mathrm{C}$ the tests are performed by cycling temperature in a range from $30^{\circ} \mathrm{C}$ to $-25^{\circ} \mathrm{C}$ in many steps using a climate controlled chamber. At each step a slowly varying $(f=0.1 \mathrm{~Hz})$ magnetic field of about 600 to $800 \mathrm{kA} / \mathrm{m}$ is applied longitudinally or transversally to the samples long axis (in plane) using a small electromagnet with adjustable poles. The magnetostrain measurements are performed after at least one-two field cycles, and represent a repeatable strain behavior in a unidirectional magnetic field. A typical strain vs. field behavior is show in fig. 3 for the three cases analyzed here at a temperature close to $M_{f}$ where the strain is maximum. The peak strain value is achieved after cooling from the austenite phase, as depicted in fig. 4, where the strain is plotted vs. field at different temperature values. From this data we can assume that developing martensite structures posses maximum mobility in cyclic field.

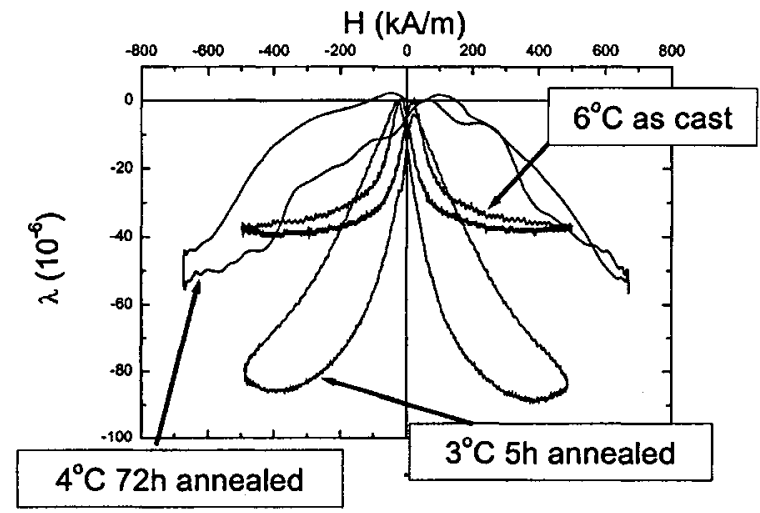

Fig. 3 Magnetically induced (unidirectional excitation) cyclic strain in the textured polycrystalline alloy $\mathrm{Ni}_{54} \mathrm{Mn}_{21} \mathrm{Ga}_{25}$ alloys before and after annealing at $800^{\circ} \mathrm{C}$ in inert gas, grain size ranging from 60 to 100 and to $150 \mu \mathrm{m}$. Strain is measured along the length of the rectangular polycrystal, and magnetic field is applied along the sample length also. Other strain gauge and field configurations were analyzed to find maximum strain. The strain vs. applied field has a rather complex behavior. The $5 \mathrm{~h}$ annealed sample presents a larger strain but also large hysteresis, similar to the single crystal case, even though the peak strain is less then $10^{-4}$, see next figure. 


\section{DISCUSSION AND SUMMARY}

The temperature related cyclic strain measured on polycrystalline NiMnGa samples (figures 3 and 4) confirms the idea that complex structural rearrangements like twin and phase boundary motion are driven by magnetic field and produce strain. The behavior of samples subjected to different annealing treatments appears rather complex (figure 3). It can be better analyzed by comparison with previously studied cases, namely those of single crystal and non oriented polycrystals. In the single crystal case a large strain (about $0.4 \%$ ) can be observed under cyclic unidirectional field conditions [7].
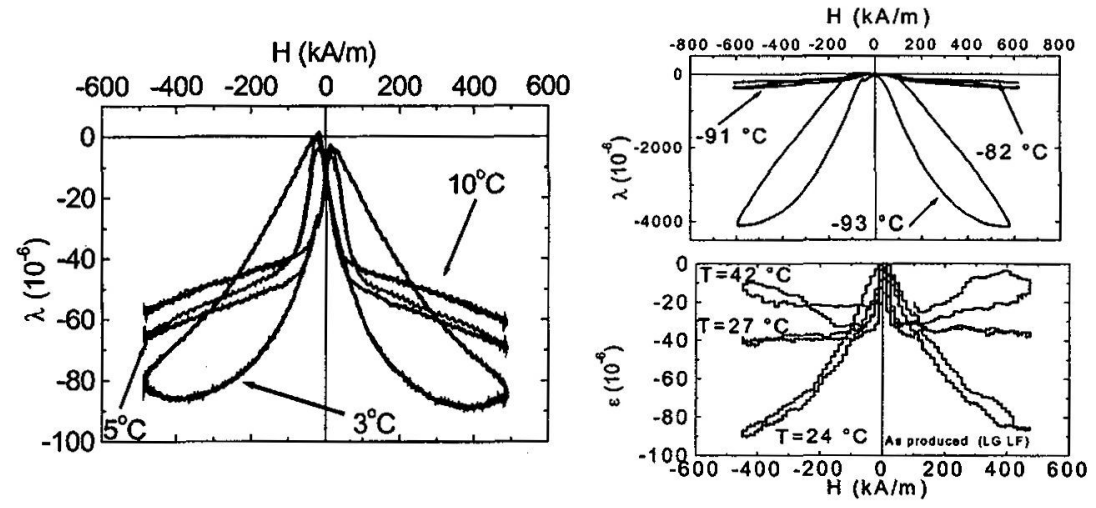

Fig. 4 (On the left) Magnetically induced strain (unidirectional excitation) at different temperatures in textured polycrystalline $\mathrm{Ni}_{54} \mathrm{Mn}_{21} \mathrm{Ga}_{25}$ alloy annealed $5 \mathrm{~h}$ at $800^{\circ} \mathrm{C}$ in inert gas, grain size $100 \mu \mathrm{m}$. The data shows a clear effect of the martensite phase transformation on cyclic strain, which sharply increases at the transition temperature. The large strain loop area shows similarities with the cyclic strain behavior of a single crystal of $\mathrm{Ni}_{2} \mathrm{MnGa}$ which is cooling through the martensite transition temperature (smaller figure top right) [7]. A reversible non hysteretic behavior would be consistent with previously observed strain loops on randomly oriented polycrystalline samples (bottom right) [8]. In this case the alloy $\mathrm{Ni}_{53} \mathrm{Mn}_{23.5} \mathrm{Ga}_{23.5}$ has an $\mathrm{M}_{\mathrm{f}}=24.3^{\circ} \mathrm{C}$.

This effect is obtained in the rearrangement of the martensite twins, when the austenite to martensite transition temperature is reached, and it is coupled with a large hysteresis in strain (see figure 4 - top right): note that in this case $\mathrm{M}_{\mathrm{s}} \approx-98^{\circ} \mathrm{C}$ and $\mathrm{A}_{\mathrm{s}}=-90^{\circ} \mathrm{C}$. On the other hand, in randomly oriented NiMnGa polycrystals, the magnetically induced strain has a reversible character, possibly produced by a quasi-elastic response to magnetization of the martensite twins (figure 4 -bottom right) [8]. In the case of grain oriented NiMnGa polycrystals, a cooperative behavior of the martensite twin boudaries, similar to the case of single crystal appears in the observed strain vs. field behavior, in a temperature range where the magnetic energy is sufficient to cause motion of the martensite twins. These results show that the orientation of the crystal grains produces a selection of the martensite twins which tend to align collectively. The small absolute value of strain may then be due either to grain-grain interactions which reduce the phase space available for twin selection and motion or to the small number of active twins. Several important issues remain now open: how to increase the absolute value of the cyclic strain in polycrystals and how to widen the temperature range where the effect is present. Also the role of lattice crystallography of a particular martensite to produce large strain should be clarified in the future.

\section{References}

[1] V.A. Chernenko, E. Cesari, V.V. Kokorin, I.N. Vitenko, "The development of new ferromagnetic shape memory alloys in NiMnGa system”, Scripta Metall. et Mater., Vol.33,pp. 1239-1244, 1995 
[2] S.J. Murray, M. Farinelli, J.K. Huang,S.M. Allen,R.C. O'Handley "Field-induced strain under load in NimNGa magnetic shape memory materials“ J. Appl. Phys., Vol. 83, p. 7297, 1998

[3] K. Bhattacharya, A. De Simone, R.D. James, C.J. Palmstrom, Proc. ICOMAT'98 Materials Science \& Engineering A273-275,pp. 685-689, 1999

[4] M.Marioni, S.M. Allen, R.C.O'Handley, T.A. Lograsso. $6 \%$ magnetic-field-induced strain by twinboundary motion in ferromagnetic Ni-Mn-Ga . Appl.Phys.Lett.,77 (2000)886-888.

[5] Q. Pan, R.D. James "Micromagnetic observations on ferromagnetic shape memory NiMnGa system" J. Appl. Phys. 87, (May 2000) pp. 4702-4706

[6] L. Manosa, A. Gonzales-Comas, E. Obrado, A. Planes,V.A. Chernenko, V.V. Kokorin, E. Cesari. "Anomalies related to the TA2 - phonon - mode condensation in the Heusler Ni2MnGa alloy" Phys.Rev.B, 1997 - I, v.55, N 17, 11068-11071.

[7] V.A. Chernenko, V.A. L'vov, M. Pasquale, S. Besseghini, C.P. Sasso, D.A. Polenur "Magnetoelastic behaviour of Ni-Mn-Ga martensitic alloys". Int. J. of Appl. Electrom. and Mech., 2000 in press

[8] M. Pasquale, C. Sasso, S. Besseghini, F. Passaretti, E. Villa, A. Sciacca "NiMnGa Polycrystalline Magnetically Activated Shape Memory Alloys" presented at Intermag 2000 Toronto, IEEE Trans. Mag. in press 